\title{
Avaliação do Sistema de Monitoramento Computadorizado de Digestão In Vitro. 3. Desaparecimento da Matéria Seca e/ou FDN pela Produção de Gás ${ }^{1}$
}

\author{
Fábio Prudêncio de Campos ${ }^{2}$, Max Lázaro Vieira Bose ${ }^{3}$, Celso Boin ${ }^{4}$, Dante Pazzanese Duarte \\ Lanna $^{5}$, Jozivaldo Prudêncio Gomes de Morais ${ }^{6}$
}

\begin{abstract}
RESUMO - Os objetivos deste trabalho foram avaliar o sistema de monitoramento computadorizado da produção de gás in vitro e compará-lo com os métodos in vivo e in situ. Nos métodos de digestibilidade (MS), foram utilizadas amostras de silagens de milho com alto/baixo teor de MS, com/sem inoculante. Avaliando a digestibilidade das silagens, pelo gás produzido na fermentação, os resultados da extensão da degradação (A+D) foram: 21,5; 22,6; 22,1; e 20,9 mL de gás/100 mg MS, sem diferença significativa. Os coeficientes de determinação obtidos na produção de gás total, em relação ao potencial de degradação obtido in situ, mostraram-se elevados para silagem de milho com alta MS inoculada $\left(\mathrm{R}^{2}=0,99\right)$, alta MS não-inoculada $\left(\mathrm{R}^{2}=0,98\right)$, baixa MS inoculada $\left(\mathrm{R}^{2}=0,94\right)$ e baixa MS não-inoculada $\left(\mathrm{R}^{2}=0,93\right)$. O desaparecimento da MS e/ou fibra em detergente neutro (FDN), quantificada pelo gás produzido no sistema in vitro/gás, apresentou resultados semelhantes aos demais métodos avaliados.
\end{abstract}

Palavras-chave: silagem de milho, digestão in vitro, produção de gás

\section{Evaluation of the In Vitro Digestion Computerized Monitoring System. 3. Dry Matter and/or Neutral Detergent Fiber Disappearance by Gas Production}

\begin{abstract}
The objective of this work was to evaluate the computerised monitoring of the in vitro gas production system and to compare with in vivo and in situ methods. In the degradation methods, corn silage samples with high/low dry matter (DM) contents, with/without inoculate, were used. Evaluating the silage degradation, by the gas production on the fermentation, the results of the extension of degradation (A+D) were 21.5; 22.6; 22.1 and $20.9 \mathrm{~mL}$ of gas/100 mg DM, without significant difference. The coefficients for determination obtained on the total gas production in relation to the potential degradation obtained in situ showed to be high for inoculated corn silage with high DM $\left(\mathrm{R}^{2}=0.99\right)$, non-inoculated corn silage high DM $\left(\mathrm{R}^{2}=0.98\right)$, inoculated corn silage with low DM $\left(\mathrm{R}^{2}=0.94\right)$ and non-inoculated corn silage with low DM $\left(\mathrm{R}^{2}=0.93\right)$. The DM and/or neutral detergent fiber (NDF) disappearance, determined by gas production in the in vitro/gas system, presented similar results when comparing the others evaluated methods.
\end{abstract}

Key Words: corn silage, gas production, in vitro digestion

\section{Introdução}

A eficiência da produção bovina intensiva é, em parte, atribuída ao balanceamento adequado da ração. A formulação de rações mais eficientes e de custo mínimo depende do valor nutritivo dos ingredientes. O surgimento de novas técnicas de avaliação de alimentos é um processo constante. No caso de bovinos, a digestão ruminal progrediu para a degradação das diversas frações alimentares, inclusive solúveis e insolúveis. Entretanto, a amostragem de material contido no rúmen, por mais freqüente que seja, sempre deixa intervalos que poderiam fornecer dados significativos. Seria, pois, ideal a medição contínua do processo digestivo, conforme estudo que vem sendo realizado pela Universidade de Cornell, com o sistema de monitoramento computadorizado da produção de gás na digestão in vitro.

Com o surgimento de novas técnicas de avaliação nutricional de alimentos e a partir dos novos sistemas de avaliação de rações com base em análises mais pormenorizadas do alimento e na fisiologia ruminal, vêm se tornando mais precisas as simulações e predições de produção animal ( FOX et al., 1990).

A digestibilidade é derivada do desaparecimento da matéria seca (TILLEY e TERRY, 1963) ou da produção total de gás (MENKE et al., 1979), após um período de incubação.

\footnotetext{
1 Projeto financiado pela FAPESP e pelo CNPq.

2 Zoot./MS - Dados parciais de Dissertação de Mestrado - ESALQ/USP; Doutorando na FCAVJ/UNESP. E.mail: fpcampos_99@yahoo.com

3 Professor aposentado no Departamento de Zootecnia - ESALQ/USP.

${ }^{4}$ Professor aposentado no Departamento de Zootecnia - ESALQ/USP.

${ }^{5}$ Professor no Departamento de Zootecnia - ESALQ/USP. E.mail: dplanna@esalq.usp.br

${ }^{6}$ Professor no Departamento de Biotecnologia Vegetal - UFSCAR. E.mail: jozivald@cca.ufscar.br
} 
TREI et al. (1970) afirmaram que a produção de gás foi altamente correlacionada com o desaparecimento da MS de milho in vitro, a produção de ácidos graxos voláteis e a digestão de amido. No sistema manométrico utilizado por TREI et al. (1970), o amido representou a grande porção do substrato; conseqüentemente, a maior porção do gás produzido. Portanto, a técnica de produção de gás in vitro oferece rápida estimativa da taxa de digestão e pode ser útil para estimar a digestibilidade dos alimentos pelos bovinos.

KHAZAAL et al. (1995), estudando a degradação da matéria seca in situ ou produção de gás in vitro, constataram que o desempenho dos animais pode ser predito com eficiência. KHAZAAL et al. (1993), em estudos de comparação do método de digestão in vitro pela produção de gás com o método in situ, avaliando a ingestão e a digestibilidade de nove fenos de leguminosas, concluíram que a predição de ingestão e digestibilidade foi mais precisa no método in situ, quando comparado com o método de produção de gás. Entretanto, consideraram que o método de produção de gás apresenta a vantagem de predizer com eficiência o desempenho do animal em comparação com outras técnicas laboratoriais de digestão in vitro.

Um sistema automático, em que a produção de gás é registrada graficamente num mapa, foi descrito por WILKINS (1974). Trabalhando nesta linha, PELL e SCHOFIELD (1993) descreveram uma técnica para facilitar os estudos de digestão in vitro, por intermédio da medição contínua da produção de gás. Assim, constataram o desaparecimento da fibra, pela medida da pressão do gás produzido em um frasco de volume fixo. MENKE e STEINGASS (1988) constataram alta relação linear entre o desaparecimento do NDF e a produção de gás.

Um fator complicante no sistema de digestão in vitro pela produção de gás está no fato de que, inicialmente, o modelo matemático baseia-se na digestão da fibra de substrato puro, enquanto o alimento apresenta uma mistura de componentes (SCHOFIELD et al., 1994). Por exemplo, FDN (GOERING e VAN SOEST, 1970) inclui hemicelulose, celulose e lignina, e esses componentes possuem diferentes taxas de digestão, bem como variam de alimento para alimento (VAN SOEST, 1994). Entretanto, o modelo matemático descrito para digestão de substrato puro pode ser também simplificado para digestão de alimentos (SCHOFIELD et al., 1994). Com as técnicas recentes de medidas computadorizadas de pequenos volumes de gases, SCHOFIELD et al. (1994) adequaram o modelo em função da quantidade de gás produzido e qualidade das curvas obtidas com os dados de produção de gás.

O modelo de produção de gás, em relação à digestão da fibra e ao crescimento microbiano, assume que a produção de massa celular bacteriana e de gás é proporcional à quantidade de substrato digerido (SCHOFIELD et al., 1994). Essa produção de gás é gerada diretamente do metabolismo de carboidrato por oxidação $\left(\mathrm{CO}_{2}\right) \mathrm{ou}$ redução $\left(\mathrm{CH}_{4}\right)$ dos produtos finais e, também, pela reação dos AGV com o tampão bicarbonato.

Os pontos críticos do método de produção de gás são: 1) pequena quantidade de amostra $(100 \mathrm{mg})$, tornando maiores os erros experimentais, 2) dificuldades na conservação e padronização de alimentos, para correção dos desvios causados pela mudança na atividade microbiana do líquido ruminal, 3) o alimento pode ter baixa produção de gás, mas na digestão in vivo pode ter alta digestibilidade e 4) $\mathrm{pH}$ dos alimentos e do líquido ruminal, no processo de digestão, pode influenciar negativamente o crescimento microbiano, acarretando menor taxa de degradação do alimento ao final da incubação (MENKE et al., 1979).

BLUMMEL et al. (1993) descrevem que o sistema é basicamente semelhante ao descrito por TILLEY e TERRY (1963), em que o substrato é incubado com líquido ruminal. A diferença está no fato de que a produção de gás é reflexo da fermentação total do substrato e, conseqüentemente, do desaparecimento da MS. Esse sistema de produção de gás oferece a vantagem de fornecer dados de duas digestibilidades dos alimentos com apenas uma incubação, na qual o volume de gás produzido pode ser indicador da digestibilidade aparente do alimento pela perda de MS, e o resíduo que sobra pode ser quantificado para se calcular a digestibilidade "verdadeira" do alimento, medida após tratamento do resíduo com detergente neutro para remoção dos microrganismos que podem ser em quantidade relativamente grande, após 24 ou 48 horas de incubação.

Visando melhor conhecimento das necessidades nutricionais de bovinos e do valor nutritivo de alimentos para arraçoamento mais eficiente, procurou-se avaliar a introdução e a viabilidade do sistema de monitoramento computadorizado da produção contínua de gás da digestão in vitro, comparando seus resultados com os obtidos pelo método de digestibilidade in situ e in vivo, utilizando-se diversas silagens de milho testadas em experimentos anteriores, com o propósito de obter dados para aplicação em futuros cálculos de rações. 


\section{Material e Métodos}

Os alimentos utilizados para correlacionar o sistema de produção de gás in vitro com o método in situ foram: silagem de milho com alto e baixo teor de matéria seca, com e sem inoculante - produto comercial à base de lactobacilos e estreptococos. A obtenção destas silagens e os procedimentos do teste de digestibilidade in vitro/gás e in situ foram descritas por CAMPOS (1996). Os alimentos foram incubados em triplicatas, com líquido ruminal de vacas holandesas e novilhos nelores fistulados no rúmen de acordo com CAMPOS (1996). Após 48 horas, avaliou-se a cinética da digestão por intermédio da produção de gás no processo fermentativo de cada alimento. Após as transformações dos dados, de milivolts para $\mathrm{mL}$ de gás, conforme metodologia descrita por CAMPOS (1996), procedeu-se à análise dos dados, por intermédio do programa estatístico "Table Curve", versão 2.0, "Jandel, Scientific, San Rafael, CA", o qual forneceu os valores de degradabilidade correspondentes às diferentes frações analisadas, segundo modelo logístico bicompartimental, proposto por PELL e SCHOFIELD et al. (1994):

$$
\begin{aligned}
\mathrm{y}= & \mathrm{A} /\{1+\mathrm{EXP}[2+4 * \mathrm{~B} *(\mathrm{C}-\mathrm{T})]\}+\mathrm{D} / \\
& \{1+\operatorname{EXP}[2+4 * \mathrm{E} *(\mathrm{C}-\mathrm{T})]\} \\
\text { em que } & \\
\mathrm{y} \quad & \text { Volume total de gás no tempo T (extensão } \\
& \text { da degradação); }
\end{aligned}
$$

A e D = volume de gás $(\mathrm{mL})$ das frações de degrada ção de rápida (açúcares solúveis e amido) e lenta digestão (celulose, hemicelulose), respetivamente;

$\mathrm{B}$ e $\mathrm{E}=$ taxas de degradações das frações de digestão rápida e lenta $(/ \mathrm{h})$, respectivamente; $\mathrm{e}$

C = tempo de colonização das bactérias (h).

Os parâmetros da cinética da digestão do feno de alfafa e das silagens de milho foram analisados sob a forma de coeficiente de variação (CV\%) em triplicatas por amostras. Os resultados obtidos dos tratamentos foram comparados com os métodos in vivo e in situ de MORAIS et al. (1996 a,b). O delineamento experimental utilizado para comparar os parâmetros da cinética da digestão foi o inteiramente casualizado, com oito repetições por tratamento em esquema fatorial $2 \times 2$ (quatro tratamentos - silagens com alta e baixa MS, inoculadas ou não). Foram feitas, também, correlações entre resultados do potencial de degradação dos métodos de digestão in situ $(\mathrm{A}+\mathrm{B})$ com a produção total de gás $(\mathrm{A}+\mathrm{D})$ no in vitro/gás.

\section{Resultados e Discussão}

Na Tabela 1, são mostrados os dados relativos à cinética da digestão de feno de alfafa, de silagem de milho com alta e baixa matéria seca inoculada ou sem inoculação, em triplicatas. Pode-se observar que, quanto maior a quantidade de carboidratos prontamente fermentecíveis (açúcares solúveis e amido) no alimento, maior o volume de gás da fração de degradação rápida $(\mathrm{A})$, fato observado nos resultados de digestão do feno de alfafa utilizada como padrão nas análises, devido aos carboidratos solúveis prontamente disponíveis para os microrganismos fermentadores, em relação às silagens que já sofreram fermentação no seu processo de confecção. Segundo STEFANON et al. (1996), a fração solúvel em água, dos carboidratos, não é bem definida quimicamente, devido às diferentes proporções de pectina, frutosanas e amido contidas nos alimentos. Entretanto, esta fração tem alto valor nutricional para os microrganismos do rúmen. Conseqüentemente, essas frações solúveis dos alimentos contribuem muito para a produção dos ácidos graxos voláteis, fonte de energia para os ruminantes.

Comparando os dados obtidos (Tabela 1) na cinética da digestão do feno de alfafa com os dados obtidos por STEFANON et al. (1996), observam-se, respectivamente, os seguintes valores das frações $\mathrm{A}=12,9 \mathrm{~mL} ; \mathrm{B}=0,12 / \mathrm{h} ; \mathrm{C}=2,2 \mathrm{~h} ; \mathrm{D}=7,6 \mathrm{~mL}$; $\mathrm{E}=0,037 / \mathrm{h} ; \mathrm{e} \mathrm{A}+\mathrm{D}=20,5 \mathrm{~mL}$ gás $/ 0,1 \mathrm{~g} \mathrm{MS}$, contra 9,$5 ; 0,17 ; 1,5 ; 10,7 ; 0,031 ;$ e 20,3 . Essa variação é atribuída, provavelmente, aos diferentes pontos de colheitas das alfafas avaliadas, bem como à sua composição bromatológica: $20,9 \%$ de $\mathrm{PB} ; 33,8 \%$ de FDN; e 25,8\% de FDA contra 22,5; 34,6; e 22,0\%, respectivamente, obtidas por STEFANON et al. (1996). Além disso, o inóculo utilizado neste trabalho foi obtido de animais consumindo alimentos diferentes dos analisados.

A amostra de silagem de milho com 41,9\% MS e $31,5 \%$ de grãos, obtida por PEREIRA (1995), quando analisadas pelo sistema in vitro/gás, apresentou volume total de gás $(\mathrm{A}+\mathrm{D})$ de $23,1 \mathrm{~mL} / 100 \mathrm{mg}$ de amostra; resultados próximos aos obtidos pelas demais silagem de milho (Tabela 1). Vários fatores interferem na digestibilidade das silagens de milho como: processamento e confecção das silagens, padrões fermentativos, maturidade da planta, cultivar utilizado, temperatura e composição bromatológica. Um fator de suma importância na avaliação de volu- 
CAMPOS et al.

Tabela 1 - Análise da produção cumulativa de gás in vitro (mL/100 mg MS) para o feno de alfafa, a silagem de milho com alta ou baixa MS, inoculada ou não no período de 48 horas obtida por triplicatas de amostras

Table 1 - Analysis of cumulative in vitro gas production ( $\mathrm{mL} / 100 \mathrm{mg} \mathrm{DM}$ ) of alfalfa hay, corn silage with high or low DM, inoculated or not in the period of 48 hours, obtained by triplicate samples

\begin{tabular}{|c|c|c|c|c|c|c|c|}
\hline \multirow[t]{2}{*}{$\begin{array}{l}\text { Forragem } \\
\text { Forage }\end{array}$} & \multicolumn{7}{|c|}{$\begin{array}{l}\text { Parâmetros da cinética de digestão } \\
\text { Kinetic parameters of the digestion }\end{array}$} \\
\hline & A & B & $\mathrm{C}$ & $\mathrm{D}$ & $\mathrm{E}$ & $A+D$ & $\mathrm{R}^{2}$ \\
\hline $\begin{array}{l}\text { Feno de alfafa } \\
\text { Alfalfa hay }\end{array}$ & 12,9 & 0,12 & 2,2 & 7,6 & 0,037 & 20,5 & 0,98 \\
\hline $\begin{array}{l}\text { Alta MS inoculada } \\
\text { High DM inoculated }\end{array}$ & 6,9 & 0,16 & 7,6 & 13,3 & 0,039 & 20,2 & 0,99 \\
\hline $\begin{array}{l}\text { Baixa MS inoculada } \\
\text { Low DM inoculated }\end{array}$ & 10,3 & 0,20 & 7,4 & 12,1 & 0,040 & 22,4 & 0,99 \\
\hline $\begin{array}{l}\text { Alta MS não-inoculada } \\
\text { High DM non inoculated }\end{array}$ & 10,7 & 0,16 & 7,4 & 12,8 & 0,042 & 23,5 & 0,99 \\
\hline $\begin{array}{l}\text { Baixa MS não-inoculada } \\
\text { Low DM non inoculated }\end{array}$ & 8,0 & 0,11 & 4,8 & 12,9 & 0,035 & 20,9 & 0,99 \\
\hline $\begin{array}{l}\text { Silagem de milho } \\
\text { Corn silage }\end{array}$ & 7,4 & 0,12 & 5,6 & 15,7 & 0,042 & 23,1 & 0,99 \\
\hline & \multicolumn{7}{|c|}{$\begin{array}{c}\text { Coeficiente de variação }(\%) \\
\text { Coefficient of variation }\end{array}$} \\
\hline $\begin{array}{l}\text { Feno de alfafa } \\
\text { Alfalfa hay }\end{array}$ & 2,3 & 8,4 & 28,7 & 6,5 & 9,0 & 3,2 & 1,56 \\
\hline $\begin{array}{l}\text { Alta MS inoculada } \\
\text { High DM inoculated }\end{array}$ & 6,1 & 18,0 & 11,5 & 6,3 & 8,4 & 5,2 & 0,07 \\
\hline $\begin{array}{l}\text { Baixa MS inoculada } \\
\text { Low DM inoculated }\end{array}$ & 6,4 & 2,6 & 5,9 & 9,5 & 4,3 & 2,2 & 0,00 \\
\hline $\begin{array}{l}\text { Alta MS não-inoculada } \\
\text { High DM non inoculated }\end{array}$ & 2,7 & 7,0 & 12,8 & 5,8 & 10,8 & 1,9 & 0,02 \\
\hline $\begin{array}{l}\text { Baixa MS não-inoculada } \\
\text { Low DM non inoculated }\end{array}$ & 8,2 & 13,5 & 32,9 & 8,1 & 7,4 & 3,5 & 0,50 \\
\hline $\begin{array}{l}\text { Silagem de milho } \\
\text { Corn silage }\end{array}$ & 5,2 & 2,2 & 7,4 & 3,0 & 6,3 & 0,8 & 0,34 \\
\hline
\end{tabular}

mosos é a temperatura ambiental em que foi produzido o volumoso. Temperaturas elevadas geralmente deprimem a digestibilidade da matéria seca dos alimentos, pelo aumento nas concentrações dos constituintes da parede celular (fibra em detergente neutro, hemicelulose, celulose), Ford et al. (1979) e Wilson (1982), citados por BUXTON e FALES (1994).

Além das fontes de variação já mencionadas, existem outras que estão ligadas aos animais doadores de inóculo ruminal, que, dependendo da categoria, do sexo e estado fisiológico, poderão apresentar diferenças no potencial fermentativo do inóculo.

MALAFAIA et al. (1998), avaliando a digestibilidade de silagens de milho, por intermédio da produção total de gás na incubação in vitro, obtiveram resultados de 52,83 $\mathrm{mL} / 360 \mathrm{mg}$ de amostra na matéria seca. Este valor, quando convertido para 100 mg de amostra, correspondeu a $14,7 \mathrm{~mL}$ de gás, produção abaixo do obtido neste trabalho $(\mathrm{A}+\mathrm{D}=$ 23,1 mL de gás). As possíveis diferenças obtidas são em função dos fatores de variação supracitados. Nas diferenças metodológicas das mensurações cumulativas dos gases, os sistemas manométricos e volumétricos são realizados manualmente em tempos espaçados e as efetuadas por sensores de pressão são automatizadas e contínuas. MALAFAIA et al. (1998) afirmam que as variações encontradas para as leituras de gás foram em função da menor produção gasosa, durante os períodos iniciais de incubação, e também da pouca sensibilidade da escala do manômetro utilizado.

As digestibilidades das silagens de milho com alta ou baixa matéria seca inoculadas ou sem inoculação mostraram-se similares quanto aos parâmetros $\mathrm{D}, \mathrm{E}$ e $\mathrm{A}+\mathrm{D}$ da cinética de digestão. Foi observado que a silagem com alta matéria seca não-inoculada apresentou maior volume de gás na fração de degradação rápida $(\mathrm{A}=10,7 \mathrm{~mL}$ de gás $)$, quando comparada com a silagem inoculada $(6,9 \mathrm{~mL}$ de gás). Ambas apresentaram taxas de degradação da fração de digestão rápida semelhantes $(B=0,16 / h)$, volume de gás na fração de degradação lento $(\mathrm{D}=13,3$ contra $12,8 \mathrm{~mL}$ 
de gás), taxa de degradação da fração de digestão lenta $(E=0,039$ contra $0,042 / h)$ e tempo de colonização das bactérias $(\mathrm{C}=7,6$ contra $7,4 \mathrm{~h})$ praticamente semelhante. A silagem com alta matéria seca sem inoculação, porém, apresentou maior produção total de gás em relação à alta MS inoculada $(A+D=23,5$ contra $20,1 \mathrm{~mL}$, respectivamente). Pode-se verificar também que houve maior coeficiente de variação para silagem com alta MS inoculada $(\mathrm{A}+\mathrm{D}=5,2 \%)$ em relação à alta $\mathrm{MS}$ não-inoculada $(\mathrm{A}+\mathrm{D}=1,9 \%)$. Nessas condições, pode-se deduzir que, apesar de ambas terem alta matéria seca, há, conseqüentemente, maiores proporções de grãos e, portanto, mais amido. $\mathrm{O}$ inoculante de certa forma influiu no crescimento microbiano, produzindo menos gás, fato ocorrido também na digestibilidade, pelo resíduo no método in situ, em avaliações realizada por CAMPOS (1996). A variação ocorrida na fração de degradação rápida (A) da silagem com alta MS deve-se, provavelmente, à interferência do inoculante utilizado na silagem, o qual deprimiu a digestibilidade da fração de digestão rápida ou se utilizou desse substrato para seu crescimento no processo de fermentação de silagem nos silos. Para a silagem de milho com baixa matéria seca inoculada, houve maior produção de gás para a fração $\mathrm{A}$ do parâmetro cinético da digestão, provavelmente, pela maior disponibilidade dos açúcares solúveis que interagiram com o inoculante bacteriano, proporcionando estes resultados.

As variações dos dados de digestibilidade in vitro (mL de gás produzido), dentro de triplicatas de amostras (Tabela 1), eram esperadas, devido a efeitos de inóculos, ao tipo de alimento a ser colocado para ser digerido (volumoso natural ou fermentado), tipo de alimento ingerido pelo animal doador (especificidade do microrganismos), bem como à categoria animal utilizado. SCHOFIELD e PELL (1995) encontraram diferenças significativas, ao usarem diferentes inóculos de líquido ruminal, e relataram que a diferença encontrada pode ter sido em função das diferentes quantidades e espécies de microrganismos no inóculo. Nesta mesma linha de pesquisa, NELSON et al. (1973) encontraram diferença significativa $(\mathrm{P}<0,01)$ na digestibilidade da matéria seca in vitro de alimentos com inóculos de vacas consumindo alimentos diferentes das analisadas. JUNG e VAREL (1995) mostraram claramente que a fonte de forragem tem efeito significativo sobre a população microbiana ruminal e subseqüente atividade fibrolítica do inóculo ruminal. CHERNEY et al. (1993), estudando a influência de vacas doadoras de líquido ruminal e fonte de fibra sobre a digestibilidade in vitro da MS de silagem de milho e alfafa, com período de incubação de 48 horas, concluíram que a fonte de fibra na dieta de vaca doadora de líquido ruminal pode afetar a digestibilidade in vitro.

Os coeficientes de variação dos dados comumente obtidos nos ensaios experimentais dão idéia da precisão dos experimentos. De maneira geral, pode-se dizer que os coeficientes de variação obtidos (Tabela 1) foram de valores de baixo a médio, salvo algumas exceções.

Para certos alimentos e parâmetros da cinética de digestão avaliados, houve coeficiente de variação considerado relativamente alto, mas essa variação pode ser explicada por problemas de quantidades e tipo de amostras, tipo e quantidade de microrganismo do inóculo (potencial de fermentação). Entretanto, apesar destas variações, os resultados da extensão de degradação (produção média de gás - $\mathrm{A}+\mathrm{D}$ ) das silagens de milho ficaram próximas $(20,2 ; 22,4 ; 23,5$; 20,9; e 23,1 mL de gás).

A importância do tipo de alimento ingerido pelo animal doador de líquido ruminal é citada por NELSON et al. (1973), que, trabalhando com digestibilidade de MS in vitro de feno de alfafa e silagem de milho, encontraram diferença significativa $(\mathrm{P}<0,01)$ na digestibilidade da matéria seca, quando utilizaram dois animais como fontes doadoras de inóculo ruminal. Entretanto, esta diferença e possíveis variações ocorrem, quando são comparadas com dados in vivo.

Ao se avaliarem os parâmetros da cinética da digestão (Tabela 2) de oito repetições de cada alimento, obtidas de todas as rodadas das análises, mesmo com descarte dos piores dados, o coeficiente de variação, ainda assim, aumentou, o que se deve à heterogeneidade da fonte de inóculo e ao $\mathrm{pH}$ do líquido ruminal. Provavelmente, o alto coeficiente de variação da digestibilidade da fração de degradação rápida (A) da silagem com baixa MS inoculada ou sem inoculação não evidenciou a diferença estatística de 7,6 contra $8,2 \mathrm{~mL}$ gás $/ 100 \mathrm{mg}$ de amostra.

Avaliando os dados das Tabelas 2 e 3, observa-se que a fração de degradação rápida (A) apresentou melhor resultado em silagens com teor de MS alto em relação ao baixo teor de MS (10,5 contra 7,9 mL de gás, respectivamente). Essa diferença pode ser atribuída ao fato de que a silagem com alta MS continha maior proporção de amido fermentescível que a silagem com baixa MS. Não houve efeito de inoculação sobre a digestibilidade dos alimentos estudados (Figura 1). As diferenças ocorridas na taxa de degradação da 
Tabela 2 - Média da produção cumulativa de gás in vitro ( $\mathrm{mL} / 100 \mathrm{mg} \mathrm{MS})$ de silagem de milho com alta ou baixa MS inoculada ou não no período total de 48 horas, obtida por oito repetições de cada forragem

Table 2 - Mean of cumulative gas production in vitro ( $\mathrm{mL} / 100 \mathrm{mg} D \mathrm{M}$ ) of corn silage with high or low DM inoculated or not in the total period of 48 hours, obtained from eigth replicates of each forage

Forragem

Parâmetros da cinética de digestão

Forage

Kinetic parameters of the digestion

\begin{tabular}{lcccccc} 
& $\mathrm{A}$ & $\mathrm{B}$ & $\mathrm{C}^{*}$ & $\mathrm{D}$ & $\mathrm{E}^{*}$ & $\mathrm{~A}+\mathrm{D}$ \\
\hline $\begin{array}{l}\text { Alta MS inoculada } \\
\text { High DM inoculate }\end{array}$ & $10,1^{\mathrm{a}}$ & $0,16^{\mathrm{a}}$ & $7,4^{\mathrm{a}}$ & $11,7^{\mathrm{b}}$ & $0,037^{\mathrm{b}}$ & $21,8^{\mathrm{a}}$ \\
$\begin{array}{l}\text { Baixa MS inoculada } \\
\text { Low DM inoculate }\end{array}$ & $7,6^{\mathrm{b}}$ & $0,21^{\mathrm{a}}$ & $9,1^{\mathrm{a}}$ & $15,2^{\mathrm{a}}$ & $0,039^{\mathrm{b}}$ & $22,8^{\mathrm{a}}$ \\
$\begin{array}{l}\text { Alta MS não inoculada } \\
\text { High DM non inoculate }\end{array}$ & $10,8^{\mathrm{a}}$ & $0,14^{\mathrm{b}}$ & $8,7^{\mathrm{a}}$ & $11,6^{\mathrm{b}}$ & $0,071^{\mathrm{a}}$ & $22,4^{\mathrm{a}}$ \\
$\begin{array}{l}\text { Baixa MS não inoculada } \\
\text { Low DM non inoculated }\end{array}$ & $8,2^{\mathrm{b}}$ & $0,12^{\mathrm{b}}$ & $6,2^{\mathrm{b}}$ & $12,8^{\mathrm{a}}$ & $0,033^{\mathrm{b}}$ & $21,0^{\mathrm{a}}$ \\
\hline Coeficiente de variação $(\%)$ & 32,9 & 27,5 & 21,6 & 18,3 & 58,7 & 7,9
\end{tabular}

Coefficient of variation

* Houve interação (MS x Inoculação)

Médias, na coluna, seguidas de mesmas letras não diferem $(P<0,05)$ pelo teste Tukey.

* There was interaction (DM $x$ Inoculation).

Means, within a column, followed by the same letter do not differ (P>.05) by Tukey Test.

Tabela 3 - Efeito isolado dos tratamentos na média da produção cumulativa de gás in vitro (mL/ $100 \mathrm{mg}$ MS) de silagem de milho com alta ou baixa MS inoculada ou não no período total de 48 horas, obtida por oito repetições de cada forragem

Table 3 - Isolated effect of treatments in the average of cumulative production of gas in vitro $(\mathrm{mL} / 100 \mathrm{mg}$ $D M$ ) of corn silage with high or low DM inoculated or not in the period total of 48 hours, obtained from eigth replicates of each forage

Matéria seca Parâmetros da cinética de digestão

Dry matter

Kinetic parameters of the digestion

\begin{tabular}{|c|c|c|c|c|c|c|}
\hline & A & B & $\mathrm{C}$ & D & $\mathrm{E}$ & $\mathrm{A}+\mathrm{D}$ \\
\hline Silagem alta MS & $10,5^{\mathrm{a}}$ & $0,15^{\mathrm{a}}$ & - & $11,7^{\mathrm{b}}$ & - & $22,2^{\mathrm{a}}$ \\
\hline Silage high DM & & & & & & \\
\hline Silagem baixa MS & $7,9^{\mathrm{b}}$ & $0,17^{\mathrm{a}}$ & - & $14,0^{\mathrm{a}}$ & - & $21,9^{\mathrm{a}}$ \\
\hline Silage low DM & & & & & & \\
\hline $\begin{array}{l}\text { Inoculação } \\
\text { Inoculation }\end{array}$ & & & & & & \\
\hline Silagem inoculada & $8,9^{\mathrm{a}}$ & $0,18^{\mathrm{a}}$ & - & $13,5^{\mathrm{a}}$ & - & $22,4^{\mathrm{a}}$ \\
\hline $\begin{array}{l}\text { Silage inoculate } \\
\text { Silagem não-inoculada } \\
\text { Silage non inoculate }\end{array}$ & $9,5^{\mathrm{a}}$ & $0,13^{b}$ & - & $12,2^{\mathrm{a}}$ & - & $21,7^{\mathrm{a}}$ \\
\hline
\end{tabular}

Médias, na coluna, seguidas de mesmas letras não diferem $(\mathrm{P}<0,05)$ pelo teste Tukey.

Means, within a column, followed by the same letter do not differ $(P>05)$ by Tukey Test. 
Rev. bras. zootec.

fração de rápida digestão (B), para inoculante e interações, e na taxa de degradação da fração de lenta digestão (E) e tempo de colonização (C), nas diversas silagens estudadas, não contribuíram para diferenciar a máxima produção de gás $(\mathrm{A}+\mathrm{D}=\mathrm{mL} / 100 \mathrm{mg}$ de $\mathrm{MS})$ dos tratamentos estudados.

SANDERSON (1993) verificou que a inoculação com bactérias lácticas não afetou a deterioração da silagem de milho e a digestibilidade da fibra. Variáveis resultantes a partir deste estudo e outros efeitos relativos à estabilidade aeróbica e digestibilidade da fibra da silagem sugerem que os inoculantes bacterianos deveriam ser vistos primeiramente como auxiliares da fermentação. Portanto, os resultados obtidos no presente experimento estão de acordo com os obtidos por MORAIS et al. (1996ab), cujas amostras foram sub-

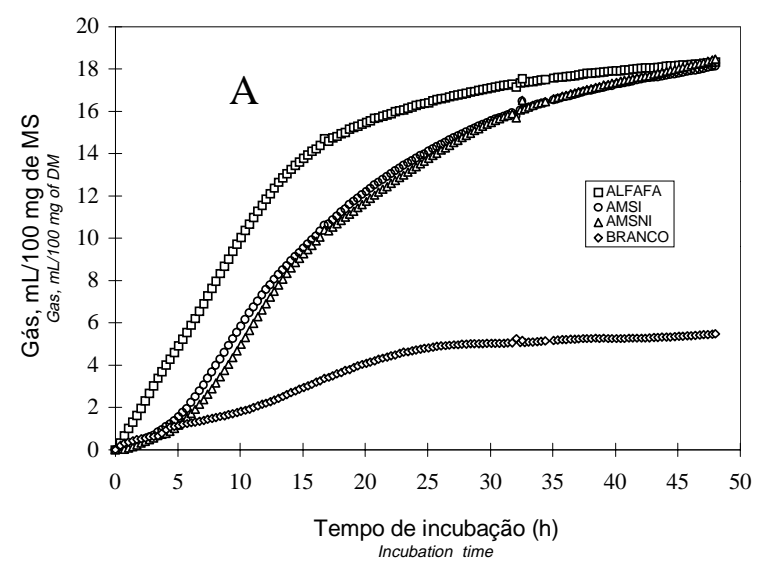

metidas à digestão in vitro neste trabalho.

$\mathrm{Na}$ tentativa de comparar os dados dos diversos sistemas, foram realizadas correlações entre os métodos de digestibilidade. A produção de gás $(\mathrm{A}+\mathrm{D})$ correlacionada com potencial de degradação $(A+B)$ obtido in situ, no tempo 48 horas, mostrou-se alta para silagem de milho com alta MS inoculada $\left(R^{2}=0,99\right)$, alta MS não-inoculada $\left(R^{2}=0,98\right)$, baixa MS inoculada $\left(R^{2}=0,94\right)$ e baixa MS não-inoculada $\left(R^{2}=0,93\right)$.

BLUMMEL et al. (1993), comparando a digestibilidade in vitro pelo processo de produção de gás com o método de digestão in situ, utilizando palha tratada com amônia, encontraram baixa correlação $(\mathrm{R}=0,29)$ entre a taxa de produção de gás in vitro e a taxa de degradação da MS (desaparecimento da MS) obtidas in situ.

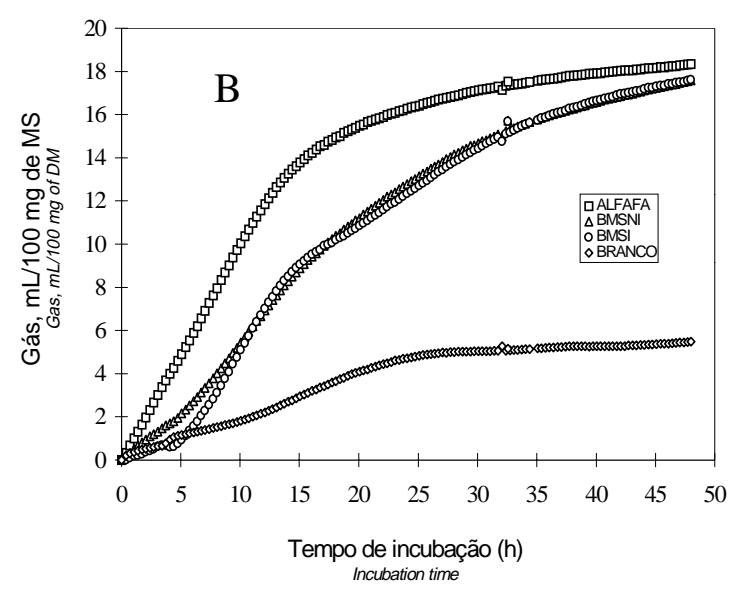

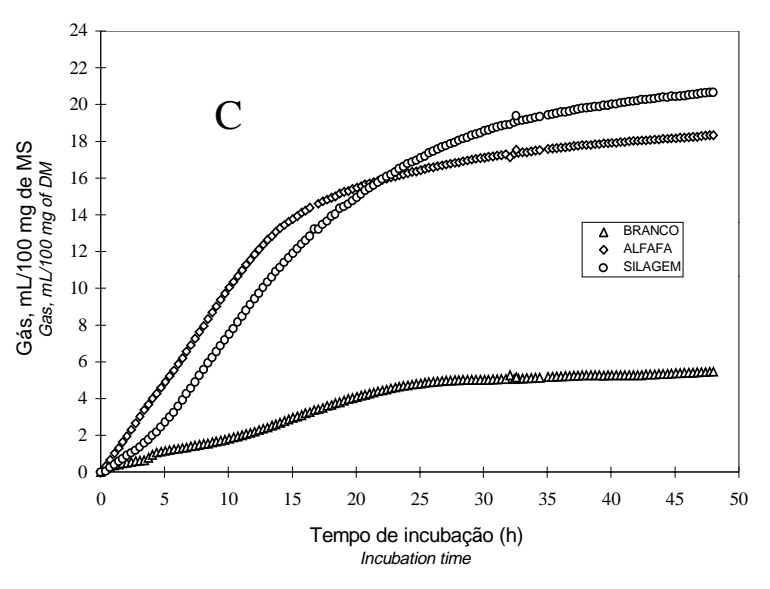

Figura 1 - Produção média de gás cumulativa (mL/100 mg de MS) em 48 horas de incubação de amostras; $\mathbf{A}=$ feno de alfafa; AMSI - silagem de milho com alta MS inoculada; AMSNI - silagem de milho com baixa MS não inoculada, Branco; $\mathbf{B}$ = feno de alfafa; BMSI - silagem de milho com baixa MS inoculada; BMSNI - silagem de milho com baixa MS não-inoculada, Branco; C = feno de alfafa; silagem de milho com 41,9\% MS e 35\% grãos, Branco.

Figure 1 - Means of cumulative of gas production ( $\mathrm{mL} / 100 \mathrm{mg}$ of $\mathrm{DM}$ ) in 48 hours of incubation of samples; $A=$ alfalfa hay, $A M S I$ - corn silage with high DM inoculated; $A M S N I$ - corn silage with high DM non inoculated, Blank; $B$ = alfalfa hay; BMSI - corn silage with low DM inoculated; BMSNI - corn silage with low DM non inoculated, Blank; $C=$ alfalfa hay; corn silage with $41,9 \%$ DM and $35 \%$ grains, Blank. 
KHAZAAL et al. (1995), comparando a predição da ingestão diária de MS e digestibilidade aparente dos fenos de gramíneas com fenos de leguminosas nos métodos in situ e in vitro/gás, constataram que os parâmetros da degradação da MS in situ foram melhores que in vitro/gás. Entretanto, no método in vitro/gás, a predição de ingestão diária de alimentos e a digestibilidade da MS foram melhores que por qualquer outra técnica de análise dos componentes da fibra ou da digestibilidade in vitro de TILLEY e TERRY (1963).

\section{Conclusões}

O sistema in vitro/gás apresentou resultados relativamente idênticos aos demais métodos de digestibilidade utilizados na avaliação das silagens de milho. O método mostrou-se eficiente em mensurar a contribuição do volume de gás oriundo de carboidratos prontamente fermentecíveis (açúcares solúveis e amido) no alimento, fato que não pode ser avaliado no método in situ.

\section{Referências Bibliográficas}

BLUMMEL, M., ORSKOV, E.R. 1993. Comparison of in vitro gas production and nylon bag degradability of roughages in predicting feed intake in cattle. Anim. Feed Sci. and Tech., 40(3):109-119.

BUXTON, R.D., FALES, S.L. 1994. Planta environment and quality. In: FAHEY JR., G.C. (Ed.) Forage quality evaluation and utilization. Madison, Wisconsin, USA. p.155-199.

CAMPOS, F.P. Avaliação do sistema de monitoramento computadorizado de digestão in vitro e produção de gás comparada com os métodos in vivo e in situ. Piracicaba, SP, 1996, 61p. Dissertação (Mestrado em Agronomia) - Escola Superior de Agricultura “Luiz de Queiroz"/Universidade de São Paulo, 1996.

CHERNEY, D.J.R., SICILIANO, J.J., PELL, A.N. 1993. Tecchinal note: Forage in vitro dry matter digestibility as influenced by fiber source in the donor cow diet. J. Anim. Sci., 71(5):1335-1338.

FOX, D.G., SNIFFEN, C.J., O'CONNOR, J.D. et al. 1990. A model for predicting requerements andfeedstuffutilization. The Cornell net carbohydrate and protein system for evaluating cattle diets research: Cornell. 128p.

GOERING, K.H., VAN SOEST, P.J. 1970. Forage fiber analysis (apparatus, reagents, procedures, and some application), Washington: ARS-USDA(USDA Agricultural Handbook,379p).

JUNG, H.G., VAREL, V.H. 1988. Influence of forage type on ruminal bacterial populations and subsequent in vitro fiber digestion. J. Dairy Sci., 71(2):1526-1535.

KHAZAAL, M.T., DENTINHO, M.T., RIBEIRO, J.M. et al. 1993. A comparison of gas production during incubation with rumen contents in vitro and nylon bag degradability as predictors of apparent digestibility in vivo and the voluntary intake of hays. Anim. Prod., 57:105-112.

KHAZAAL, M.T., DENTINHO, M.T., RIBEIRO, J.M. et al. 1995. Prediction of apparent digestibility and voluntary intake of hays fed to sheep: comparison between using fibre components, in vitro digestibility or characteristics of gas production or nylon bag degradation. J. Anim. Sci., 61(3):527-538.
MALAFAIA, P.A.M., VALADARES FILHO, S.C., VIEIRA, R.A.M., SILVA, J.F.C., PEREIRA, J.C. 1998. Cinética ruminal de alguns alimentos investigada por técnicas gravimétricas e metabólicas. $R$. Bras. Zootec., 27(2):370-380.

MENKE, K.H., RAAB, L., SALEWZKI, A., etal. 1979. The estimation of the digestibility and metabolizable energy content of ruminant feedingstuffs from the gas production when they are incubated with rumen liquor in vitro. J. Agric. Sci., 93(1):217-222.

MENKE, K.H., STEINGASS, H. 1988. Estimation of the energetic feed value obtained from chemical analysis and in vitro gas production using rumen fluid. Anim. Res. Dev., 28(1):7-55

MORAIS, J.P.G., BOIN, C., CAMPOS, F.P. et al. Efeito de inoculante bacteriano em silagem de milho quanto a digestibilidade in vivo $\mathrm{e}$ fermentação. In. REUNIÃO ANUAL DA SOCIEDADE BRASILEIRA DE ZOOTECNIA, 33, 1996, Fortaleza. Anais... Fortaleza: SBZ, 1996a, p.425-427.

MORAIS, J.P.G., BOIN, C., CAMPOS, F.P. et al.Efeito na degradação in situ e na taxa de passagem de silagem inoculada com aditivo microbiano. In: REUNIÃO ANUAL DA SOCIEDADE BRASILEIRA DE ZOOTECNIA, 33, 1996, Fortaleza. Anais... Fortaleza: SBZ, 1996b, p.428-430.

NELSON, B.D., ELLZEY, H.D., MONTGOMERY, C. et al. 1973. Factors affecting the variability of an in vitro rumen fermentation technique for estimating forage quality. J. Dairy Sci., 55(3):358-366.

PELL, A.N., SCHOFIELD, P. 1993. Computerized monitoring of gas production to measure forage digestion in vitro. J. Dairy Sci., 76(4):1063-1073.

SCHOFIELD, P., PELL, A.N. 1995. Validity of using accumulated gas pressure readings to measure forage digestion in vitro: A comparasion involving three forages. J. Dairy Sci., 78(10):2230-2238.

SCHOFIELD, P., PITT, R.E., PELL, A.N. 1994. Kinetics of fiber digestion from in vitro gas production. J. Anim. Sci., 72(11):2980-2991.

STEFANON, B., PELL, A.N., SCHOFIELD, P. 1996. Effect of maturity on digestion kinetics of water-soluble and waterinsoluble fractions of alfafa and brome hay. J. Anim. Sci., 74(5):1104-1115.

TILLEY, J.M.A., TERRY, R.A. 1963. A two technique for the in vitro digestion of forage crops. J. Br. Grassl. Soc., 18:104-111.

TREI, J., HALE, W.H., THEURER, B. 1970. Effect of grain processing on in vitro gas production. J. Anim. Sci., 30(5):825-831.

VAN SOEST, P.J. 1994. Nutritional ecology of the ruminant. 2.ed. Ithaca: Cornell Press/Constock Publish. 476p.

WILKINS, J.R. 1974. Pressure transducer method for measuring gas production by microorganisms. Appl. Microbiol., 27:135-141.

Recebido em: 31/10/97

Aceito em: 27/09/99 